\title{
Assessing Status of lodine Nutrition in Union Territory of Chandigarh, India
}

\author{
${ }^{1}$ Neeraj Agarwal, ${ }^{2}$ Jasbinder Kaur, ${ }^{3}$ Jaswinder Kaur, ${ }^{4}$ Seema Gupta, ${ }^{5}$ Shivani Jaswal, ${ }^{6}$ Harjeet Kaur, ${ }^{7}$ HM Swami
}

\begin{abstract}
lodine deficiency disorders (IDDs) constitute a major public health problem in India. Goiter occurring in a large fraction of population ( $>10 \%$ ) is said to be due to iodine deficiency rather than any other cause. A community-based cross-sectional study was undertaken in the Union Territory of Chandigarh with the aim to track the elimination of IDD to determine the iodine status of school children unexamined for goiter status and excretion median urinary iodine concentration. Goiter was assessed by standard palpation technique in 6,517 school children, aged 6 to 12 years, selected through 30 cluster sampling methods. Spot urine samples of 823 children were collected for estimation of urinary iodine using modified method of Sandell and Kolthoff. Household salt samples of the 548 selected children from schools were analyzed for its iodine content by standard iodometric titration method. The overall prevalence of goiter was found to be $14.2 \%$ among the children examined. The median urinary iodine excretion (UIE) was $199 \mathrm{~g} / \mathrm{L}$. About $71.2 \%$ of the salt samples were adequately iodized, having iodine content of $>15 \mathrm{ppm}$. Since UIE reflects recent iodine nutrition at the time of measurement and thyroid size shows iodine nutrition over months or years, it can be said that this region is in transition phase from iodine-deficient to iodinesufficient territory.
\end{abstract}

Keywords: Chandigarh, Goiter prevalence, lodine deficiency disorders, Salt iodization, Urinary iodine.

How to cite this article: Agarwal N, Kaur J, Kaur J, Gupta S, Jaswal S, Kaur H, Swami HM. Assessing Status of lodine Nutrition in Union Territory of Chandigarh, India. Indian J Med Biochem 2016;20(1):38-41.

Source of support: Nil

Conflict of interest: None

\footnotetext{
${ }^{1,2}$ Professor and Head, ${ }^{3}$ Research Fellow, ${ }^{4,6}$ Assistant Professor ${ }^{5}$ Professor, ${ }^{7}$ Medical Superintendent

${ }^{1}$ Department of Community Medicine, All India Institute of Medical Sciences, Patna, Bihar, India

${ }^{2,4-6}$ Department of Biochemistry, Government Medical College and Hospital, Chandigarh, India

${ }^{3}$ Department of Neurology, John Hopkins University, Baltimore Maryland, USA

${ }^{7}$ Department of Community Medicine, Gian Sagar Institute of Medical Sciences, Banur, Punjab, India

Corresponding Author: Jasbinder Kaur, Professor and Head Department of Biochemistry, Government Medical College and Hospital, Chandigarh, India, Mobile: +919646121532, e-mail: jasbinderkaur@yahoo.co.in
}

\section{INTRODUCTION}

Iodine is an important micronutrient required for human nutrition. Lack of iodine in the diet leads to visible and invisible spectrum of health consequences, collectively called iodine deficiency disorders (IDDs). ${ }^{1}$ It was estimated that 1.9 billion people from 130 countries are at risk of developing IDD. ${ }^{2}$ In India also, IDD has been identified as a public health problem with 200 million people at risk. ${ }^{3}$ Two major factors responsible for IDD are inadequate iodine intake and inadequate iodine utilization. The inadequate iodine intake may be secondary to low iodine content of the soil or inadequate consumption of sea food due to high cost and low availability. The presence of certain goitrogens in some foods may lead to inadequate utilization. Endemic goiter is surface manifestation of iodine deficiency. An area is considered to be having endemic goiter if the prevalence is more than $5 \%$ in the age group of 6 to 12 years. ${ }^{4}$

In 1992, the National Goitre Programme was renamed as National Iodine Deficiency Disorder Control Programme (NIDDCP) in view of covering wide spectrum of IDDs, such as mental and physical retardation, deaf mutism, still births, and abortions. ${ }^{5}$ Under this program, iodized salt containing $15 \mathrm{ppm}$ of iodine is made available to the beneficiaries. ${ }^{6}$ Most of the iodine absorbed in the body eventually appears in urine, so urinary iodine concentration is a good marker for estimating very recent dietary iodine intake. ${ }^{7}$

The objective of the present study was to assess the status of iodine nutrition of the population by measuring urinary iodine excretion (UIE) in the children of age group 6 to 12 years. The study also aimed to estimate the iodine content of salt at the household level. It is hypothesized that the iodine nutrition in schoolgoing children of Chandigarh should be optimal and, hence, goiter prevalence to be less than $10 \%$, as iodized salt is freely available these days.

\section{MATERIALS AND METHODS}

The study was conducted in the year 2006-2008 by the Departments of Community Medicine and Biochemistry, Government Medical College and Hospital, Chandigarh. The study was approved by ethics committee of the institution. The study design was observational and cross-sectional. 
The study group comprised school going children in the age group of 6 to 12 years. The sample size was calculated to be 6,600, taking the prevalence of goiter as $20 \%$, with allowable error of $6 \%$, and design effect of 1.5 .

Prior permission was obtained from Director, Public Instruction Schools. Detailed information was provided, prior to survey, to principals of school regarding the activity and informed consent for participation of the student was obtained from parents/guardians.

The sampling method was probability proportional to size (PPS) 30 cluster methodology. After listing all the primary schools of Union Territory of Chandigarh, 30 schools were selected using 30 cluster methods. It was planned to conduct surveys among $220(30 \times 220=6,600)$ students of the study group. All students were notified in advance to bring their household salt sample. Using systematic sampling, every 10th student was asked to give salt sample for further analysis of iodine content in the lab.

Every 7th student, as per systematic sampling, was requested to provide the urine sample for UIE.

During the survey, a health talk on IDD was conducted among school children and teacher. They were given a demonstration on checking the qualitative iodine testing in salt using the onsite kit.

All children in the study group were physically examined by senior resident/demonstrator for the presence of goiter using the WHO classification. ${ }^{8}$

Grade 0 - No palpable or visible goiter

Grade 1 - Palpable but not visible goiter

Grade 2 - Palpable and visible goiter

Assessment of urinary iodine was done by an assay based on the Sandell-Kolthoff reaction. ${ }^{9}$

The children were divided into groups according to urinary iodine levels ${ }^{10}$

$<20 \mu \mathrm{g} / \mathrm{L} \quad-$ Severe iodine deficiency

20-49 $\mu \mathrm{g} / \mathrm{L}$ - Moderate iodine deficiency

50-99 $\mu \mathrm{g} / \mathrm{L}$ - Mild iodine deficiency

$\geq 100 \mu \mathrm{g} / \mathrm{L}$ - Iodine-replete state

Household salt samples were analyzed for its iodine content using the standard iodometric titration method. ${ }^{11}$ Statistical analysis of the data was done by MannWhitney U-test and chi-square test. A p-value $<0.05$ was considered to be statistically significant.

\section{RESULTS}

A total of 6,517 children from 30 schools could be screened for thyroid enlargement. A total of 900 urine samples were collected; of which, only 823 were analyzed for urinary iodine concentration. A total of 77 were discarded due to low quantity, sediments, or turbidity. Salt samples from 584 households were titrated for iodine content.
Table 1: lodine status assessment indicators of children in Chandigarh

\begin{tabular}{ll}
\hline Indicator & Value (\%) \\
\hline Total goiter rate & $14.2 \%(95 \% \mathrm{Cl}: 13.4-15.1)$ \\
$\quad$ Goiter grade I & $14 \%(95 \% \mathrm{Cl}: 13.2-15.1)$ \\
$\quad$ Goiter grade II & $0.2 \%(95 \% \mathrm{Cl}: 0.1-3.1)$ \\
UIE $(\mu \mathrm{g} / \mathrm{L})($ median $)$ & $199 \mu \mathrm{g} / \mathrm{L}(15.2-337 \mu \mathrm{g} / \mathrm{L})$ \\
$\quad$ Proportion $<100 \mu \mathrm{g} / \mathrm{L}$ & $26 \%(95 \% \mathrm{Cl}: 23-29)$ \\
$\quad$ Proportion $<50 \mu \mathrm{g} / \mathrm{L}$ & $13.3 \%(95 \% \mathrm{Cl}: 10.9-15.6)$ \\
Proportion of households & $71.2 \%(95 \% \mathrm{Cl}: 67.5-74.9)$ \\
consuming adequate iodized & \\
\hline (>15 ppm) salts & \\
\hline
\end{tabular}

Table 2: Distribution of iodine content of salts at household level in Chandigarh

\begin{tabular}{lll}
\hline lodine content (PPM) & Number of samples & Percentage \\
\hline 0 & 0 & 0 \\
$<15$ & 168 & 28.8 \\
$15-29.9$ & 321 & 54.9 \\
$\geq 30$ & 95 & 6.3 \\
\hline Total & 584 & 100 \\
\hline
\end{tabular}

In this study, $55.9 \%$ boys and $44.1 \%$ girls participated in age group of 6 to 9 years $(66.7 \%)$ and 9 to12 years $(33.3 \%)$. The total goiter rate was $14.2 \%$ (95\% CI: $13.4-15.1)$, prevalence of grade 1 goiter being $14.0 \%$ (95\% CI: $13.2-$ 14.8 ) and grade 2 being $0.2 \%$ (95\% CI: $0.1-3.1)$ (Table 1$)$.

After analysis of 823 urine samples, median UIE concentration was found to be $199 \mathrm{\mu g} / \mathrm{L}$ with a range from 15.2 to $337 \mu \mathrm{g} / \mathrm{L}$. The UIE below $100 \mu \mathrm{g} / \mathrm{L}$ was found in 26\% (95\% CI: 23-29) children and proportion of children with a UIE below $50 \mu \mathrm{g} / \mathrm{L}$ was $13.3 \%$ (95\% CI: 10.9-15.6).

Analysis of level of salt iodization showed that $71.2 \%$ of the samples were adequately iodized with iodine content of $>15$ ppm $(54.9 \%$ had $15-30$ ppm and 16.3\% had $>30 \mathrm{ppm}$ ). As much as $28.8 \%$ of the salt samples had iodine content between 5 and $15 \mathrm{ppm}$, showing inadequate iodization. None of the households was consuming salt with iodine content of $<5 \mathrm{ppm}$ (Table 2).

\section{DISCUSSION}

The prevalence of endemic goiter in school children in the age group of 6 to 12 years is the most widely accepted marker to evaluate the severity of IDD in a region. It is an index to the degree of long-standing iodine deficiency and actually indicates the long-term iodine nutritional status in a population. In our study, overall prevalence of goiter was found to be $14.2 \%$. According to the WHO recommendations, an area with prevalence rate of 5.0 to $19.9 \%$ is considered as mildly endemic, whereas areas with prevalence rate of 20 to $29.9 \%$ and $>30 \%$ are considered as moderately and severely endemic for goiter 
Table 3: Criteria for tracking progress toward iodine nutrition eliminating iodine deficiency disorder as a public health problem in Union Territory of Chandigarh

\begin{tabular}{lll}
\hline Indicator & Goal & Union Territory \\
\hline 1 Thyroid enlargement & & \\
(Age group, 6-12 years) & $<5 \%$ & $14.2 \%$ \\
2 Urinary iodine & & \\
Median urinary iodine excretion $(\mu \mathrm{g} / \mathrm{L})$ & $>100$ & 199 \\
Proportion below $100 \mu \mathrm{g} / \mathrm{L}$ & $<50 \%$ & $26 \%$ \\
Proportion below $50 \mu \mathrm{g} / \mathrm{L}$ & $<20 \%$ & $13.3 \%$ \\
3 Salt iodization & & \\
Proportion of households consuming & $>90 \%$ & $71.2 \%$ \\
adequately iodized salt $(\geq 15 \mathrm{ppm})$ & & \\
\hline
\end{tabular}

respectively. ${ }^{12}$ This suggested that IDD is a mild public health problem in this region and was contrary to our hypothesis (Table 3 ).

Urinary iodine excretion is an important biochemical marker for the assessment of IDD as 90\% of iodine excretion is through urine. ${ }^{13}$ Urinary iodine excretion indicates very recent iodine intake and is an index of choice for evaluating the degree of iodine deficiency and its correction. The WHO recommends that at least $50 \%$ of population achieving UIE of $100 \mu \mathrm{g} / \mathrm{L}$ and not more than $20 \%$ of the samples below $50 \mu \mathrm{g} / \mathrm{L}$ in an area indicates iodine-replete status among population? ${ }^{14}$ Median UIE level in our study was $199 \mu \mathrm{g} / \mathrm{L}$ and $74 \%$ of the total studied population had urinary iodine levels $\geq 100 \mu \mathrm{g} / \mathrm{L}$, indicating that there was no biochemical iodine deficiency. Similar results were found in one population-based study done in Cochin. ${ }^{15}$ In this study, UIE was estimated in 954 adult subjects and median iodine excretion value was reported as $211 \mu \mathrm{g} / \mathrm{L}$, suggesting that the population was iodine sufficient.

The WHO recommends that $90 \%$ of the household salts should get iodized at the recommended level of $15 \mathrm{ppm},{ }^{16}$ but our study showed that only $71.2 \%$ households were consuming adequately iodized salt. A study conducted by Dhaar et al. ${ }^{17}$ also reported that $73.15 \%$ of 18,011 salt samples analyzed confirmed to the prescribed standards. This indicates that even if iodine nutrition seems to be appropriate by optimal UIE levels at this point of time, still it is possible that iodine deficiency can emerge as public health problem in future.

A study conducted by Kapil et al. ${ }^{18}$ in Delhi showed similar results where $88.7 \%$ of the study population had more than $100 \mu \mathrm{g} / \mathrm{L}$ and $2.6 \%$ had less than $50 \mu \mathrm{g} / \mathrm{L}$ daily UIE. In their study, $16 \%$ of families were consuming salt with iodine content $<5 \mathrm{ppm}$ as compared to our study where no family was consuming salt having iodine content $<5$ ppm. During 1994 to 2002, Human Nutrition Unit, AIIMS, collected a total of 24,798 salt samples from various research surveys from more than 160 districts of 13 states of the country. These salt samples were analyzed using the standard iodometric titration method. Their findings indicated that the salt iodization in India was within the safe limits. ${ }^{19}$

However, Patro et al. ${ }^{20}$ in their study concluded that adequate salt iodization in Jharkhand was only $64.2 \%$ but total goiter rate was $0.9 \%$ only with median UIE of $173.2 \mathrm{\mu g} / \mathrm{L}$. Another study conducted by Das et al. ${ }^{14}$ in West Bengal reported TGR 13.7\% and median UIE level of $130 \mu \mathrm{g} / \mathrm{L}$ and $80 \%$ salt samples having adequate iodine content.

The results of our study also point toward changing pathogenesis of goiter to immunological, hereditary, or infectious causes. Also, in India, large numbers of cyanogenic plants are used as common vegetables and thus IDD persists in many regions in spite of recommended iodine intake. Indian cyanogenic plant foods have potential antithyroid activity and supplementation of extra iodine fails to counteract their effect. ${ }^{21}$ In this region, people also consume vegetables of Brassica family, spinach, and others, which have presence of goitrogens that can interfere with iodine metabolism by competitive inhibition of iodide transport into the thyrocyte. Biswas et al. ${ }^{22}$ found a significant positive correlation between urinary iodine and urinary thiocyanate concentrations suggesting that when consumption of thiocyanate is increased as evidenced by increased urinary thiocyanate levels, the excretion of iodine almost increased proportionally.

\section{CONCLUSION AND RECOMMENDATION}

The population in Union Territory is having sufficient iodine nutrition at present, but continuous efforts are needed to sustain the availability and utilization of iodized salt to keep iodine nutrition at optimum level.

It is recommended that intensified information, education, and communication activities, along with further strengthening the system of monitoring the quality of iodized salt provided to the beneficiaries should be continued to progress toward elimination of IDD. The shortcoming of our study is the palpation method for goiter detection, which could have led to overdiagnosis of grade I goiter by the investigators.

\section{ACKNOWLEDGMENTS}

Authors acknowledge the financial support from the Department of Science and Technology, Chandigarh, for carrying out this work. The cooperation provided by Director, Public Instruction Schools, principals, and the Education Department of Chandigarh to allow the investigators to recruit school students for the study is thankfully acknowledged. 


\section{REFERENCES}

1. El-Mougi FA, Abd-El-Ghaffar S, Fayek NA, Mohammed MS. Urinary iodine and other iodine deficiency indicators in a sample of school-age children in Egypt. East Mediterr Health J 2004 Nov;10(6):863-870.

2. Lim KK, Wong M, Mohamed WN, Kamaruddin NA. Iodised salt supplementation and its effect on thyroid status amongst Orang Asli in Hulu Selangor, Malaysia. Asia Pac J Clin Nutr 2013;22(1):41-47.

3. Revised Policy Guidelines on National Iodine Deficiency Disorder Control Programme, IDD \& Nutrition Cell. MOHFW. 2006 Oct; p. 1, 2.

4. Delange FM, Dunn JT. Iodine deficiency. In: Braverman LE, Utiger RD, editors. Werner and Ingbar's the thyroid: a fundamental and clinical text. 9th ed. Philadelphia (PA): Lippincott Williams and Wilkins; 2006. p. 264-287.

5. The Journey National Rural Health Mission, UT, Chandigarh [Internet]. [Accessed 2015 May 18]. p. 59-63. Available from: http://nrhmchd.gov.in/bandhan_pyar_ka.pdf.

6. Bhasin SK, Kumar P, Dubey KK. Comparison of urinary iodine excretion and goitre survey to determine the prevalence of iodine deficiency. Indian Pediatr 2001 Aug;38(8):901-905.

7. Delange F, Benoist B, Burgi H. ICCIDD Working group. Determining median urinary iodine concentration that indicates adequate iodine intake at population level. Bull World Health Organ 2002;80(8):633-636.

8. McDonnell CM, Harns M, Zacharin MR. Iodine deficiency and goitre in school children in Melbourne, 2001. Med J Aus 2003 Feb 17;178(4):159-162.

9. Pino S, Fang SC, Bravermen LE. Ammonium per sulphate: a safe alternative oxidizing reagent for measuring urinary iodine. Clin Chem 1996 Feb;42(2):239-243.

10. Assessment of iodine deficiency disorders and monitoring their elimination [Internet]. A guide for programme managers. 2nd ed. Geneva: WHO; 2001 [accessed 2016 July 4]. Available from: http://www.who.int/nutrition/publications/micronutrients/ iodine_deficiency/9789241595827/en/.
11. Karmakar MG, Pandav C, Krishnamachari KAVR. Principle and procedure for iodine estimation: a laboratory manual. New Delhi: ICMR; 1986. p. 1-3.

12. Laway BA, Zargar AH. Iodine deficiency disorders in India. J Indian Med Assoc 2006 Oct;104(10):554-556.

13. Dunn JT, Vander Haar F. Detection of iodine deficiency. In: A practical guide to the correction of iodine deficiency. Technical Manual No. 3; 1990. p. 13-20 [accessed 2016 July 4]. Available from: http:/ / www.who.int/nutrition/publications / micronutrients/iodine_deficiency/practical_guide_correction_ idd/en/.

14. Das DK, Chakraborty I, Biswas AB, Saha I, Mazumdar P, Saha S. Goitre prevalence, urinary iodine and salt iodisation level in a district of West Bengal, India. J Am Col Nutr 2008 Jun;27(3):401-405.

15. Unnikrishnan AG, Menon UV. Thyroid disorders in India: an epidemiological perspective. Indian J Endocrinol Metab 2011 Jul;15(Suppl 2):S78-S81.

16. Joint $\mathrm{WHO} / \mathrm{UNICEF} / \mathrm{ICCIDD}$ Consultation: Indicators for Assessing Iodine Deficiency Disorders and their Control Programmes. Geneva: WHO; 1992.

17. Dhaar GM, Robbani I. Nutrition problems of mother and children. In: Foundation of community medicine. India: Reed Elsevier; 2008. p. 272-280.

18. Kapil U, Sethi V, Goindi G, Pathak P, Singh P. Elimination of iodine deficiency disorders in Delhi. Indian J Pediatr 2004 Mar;71(3):211-212.

19. Kapil U, Singh P. Status of iodine content of salt and urinary iodine excretion levels in India. Pak J Nutr 2003;2(6):361-373.

20. Patro BK, Saboth P, Zodpey S, Shukla A, Karmakar MG, Pandav CS. Tracking progress toward elimination of iodine deficiency disorders in Jharkhand, India. Indian J Community Med 2008 Jul;33(3):182-185.

21. Chandra AK, Singh LH, Tripathy S, Debnath A, Khanam J. Iodine nutritional status of children in North East India. Ind J Pediatr 2006 Sep;73(9):795-798.

22. Biswas AK, Chatterjee N, Pandey A. Studies on interrelation between iodine and thiocyanate and their excretion pattern among school children in sub-Himalayan Tarai region. Int J Int Sci Inn Tech Sec B 2012;1(1):31-36. 